\title{
Ubicomp, urban space and landscape
}

\author{
R. C. F. de Souza \& M. L. Malard \\ School of Architecture of Universidade Federal de Minas Gerais, Brazil
}

\begin{abstract}
This article discusses the use of Ubiquitous Computing (Ubicomp) systems in the design of urban revitalizations and refurbishments, using a specific methodology that considers Information Technology (IT) as one more instrument to harmonize the urban scene with the landscape, minimizing the impacts that those processes can bring. The hypothesis is that when IT components and services are strategically deployed - respecting the structure of the places - they can introduce computational resources that will allow human activities to better harmonize with the landscape. This hypothesis is based on Heidegger's thoughts, when he reflects about the concept of "circumspection", meaning that when a technological apparatus works fine, its presence recedes in the human consciousness.

When components and services of $I T$ are deployed strategically in a place respecting its topological structure - those devices and services can add computational capabilities that improve human activities and make them integrated with the natural environment in a coherent and continual gradient of meaning, functionality and technological availability.

Human activities can better harmonize with nature by means of the use of ordinary objects and spatial elements that act as interfaces to access computational services, supporting the activities of a place, making them more efficient, producing less pollution, reducing their cost and energy consumption.

Mark Weiser's idea about the evolution of Ubicomp also reinforces that main hypothesis. According to him, the spread of computational resources in the environment through Ubicomp will bring a new era of calm technology in which human dwelling will be supported by intelligent environments. To test that hypothesis, a theoretical framework was developed and applied by architects in three urban projects, in cities of the United Kingdom and South Korea. Focusing on the potential within IT components to promote qualities such as territoriality, privacy, identity and ambience, three case studies were described and analyzed. There are reasons for appropriately deploying IT based on the nature of the place and the activities that happen within it. The results show that a less physically
\end{abstract}


interfering design can be achieved. Therefore, the projects become more ecological and sustainable, with more chances to harmonize with the landscape. Conclusions are drawn and possible new research is suggested.

Keywords: ubiquitous computing, urban project, architecture.

\section{Introduction}

Ubiquitous Computing (Ubicomp) is the model of human/computer interaction in which a computational capacity and its resources are accessed through the devices and services of Information Technology (IT) integrated in the environment. They are integrated by means of being embedded in ordinary objects and spaces that are tuned into interfaces so as to allow interaction with people in order to detect, respond and represent some of their needs. The most common devices and services in a Ubicomp System are microprocessors, sensors, displays, actuators and links, among others. Due to this new paradigm of integration with the space, the activities can be accurately scrutinized in terms of types of users, frequency of use, origin and destiny, personal preferences, special needs and other characteristics. This information can trigger different types of arrays of spatial elements and equipments so as to promote quick changing in the built environment, for instance, to adapt the function of the environment to new activities, or to save energy, or to improve the security, the user's satisfaction or merely to monitor the equipments.

\section{Mark Weiser and the disappearing of technology}

In the middle of the 1990s, Mark Weiser coined the term Ubiquitous Computing to refer to the conjoint of technologies that would allow that, in the near future, the computing resources would be installed in the environment and used by people within the places. That usage, according to Weiser, would not happen by means of stressing and complicating interactions, but, instead, it would be an intuitive and intelligent manner to use the components, with lots of computer spread to support the user in her/his activities, every time, everywhere. Using as interfaces the quotidian objects and spaces to access the spread computing resources, the user could thus concentrate himself better and easily in her/his main activities, putting in the periphery of her/his attention what would be out of the original focus in that moment. Weiser summarized that idea, deeming that one day computing would spread and embed in the environment. About this, he commented: "The most profound technologies are those that disappear. They weave themselves into the fabric of the everyday life until they are indistinguishable from it" [1]. He exemplified that comment using nowadays trivial facts as the use of machines that are integrating our lives, such as cars, phones and other gadgets, which we do not pay attention to. He named this technological era "Calm Technology", a future mentality, where interfaces would be designed to be intuitively used because of the existence of new technical achievements, of a massive miniaturization of components, a cost reduction and an intelligent design of those systems. 


\section{Disappearing is a psychological condition}

However Weiser, despite all the reasons of industrial design, recognized that that new era of calm technology was a consequence from a human need. He commented that: "Such a disappearance is a fundamental consequence not of technology, but of human psychology. Whenever people learn something sufficiently well, they cease to be aware of it. (...) Computer scientist, economist, and Novelist Herb Simon calls this phenomenon 'compiling'; philosopher Michael Polanyi calls it the 'tacit dimension'; psychologist TK Gibson calls it 'visual invariants'; philosophers Georg Gadamer and Martin Heidegger call it 'the horizon' and the 'ready-to-hand', John Seely Brown at PARC calls it the 'periphery'. All say, in essence, that only when things disappear in this way are we freed to use them without thinking and so to focus beyond them on new goals. "'[1]

\section{Weiser cites Heidegger: the transparency of the ready-to-hand}

This conceptual similarity with others thinkers allow us to understand, specifically through Heidegger's thoughts, the consequences of a common vision about technology, at the same time helping us to review other spatial implications [2] for the human being associated with the natural and built environment. To Heidegger [3], the term "ready-to-hand" points out a kind of entity that was turned into an equipment by means of human labor. So, elements of nature are "present-at-hand", which means they are not for a specific purpose, but when human being applies over them some labor, they are turned into equipment. The essence of equipment is being for something, which means, its essence is its finality. Heidegger observed that when we use equipment, our consciousness becomes subordinated to its function and it starts to integrate its usage itself. He called this "manipulating" which means a primeval understanding that we can have about the entities "ready-to-hand". This way to understand the world differs far from the second hand way to understand, when we know something but without ever having tried it.

\section{Characteristics of equipment in Heidegger}

To Heidegger, the meaning of an object ready-to-hand emerges from its links to others objects ready-to-hand which provides support to the human being. Since those objects are called equipment, he called these links among objects as the "equipmental nexus of the things" [3], meaning that what is an object will depend upon of its contextual functionality more than its cultural meaning, given in the time or in the space. When we are using a ready-to-hand object, we are more concerned and absorbed with our goal than with the equipment itself. Thus, when ready-to-hand objects are genuinely effective, they become "transparent" [4] and unnoticed for us. In this situation, we are not busying our mind with their 
immediate presence and our consciousness becomes a whole with the utensil we are using exactly by means of the usage. However if, instead, it breaks down and stop functioning, it starts occupying again our mind and becomes visible for us, conspicuous, requiring our attention to fix it. Our equipmental nexus of things also causes in our existence a kind of daily perceptual experience about the environment. Heidegger called it "circumspection" which means a kind of careful vision of things that do not imply in a deliberated attention in what is being done. It provokes in the subject a mental attitude where the perception of herself/himself is indistinguishable from the totality she/he makes with the action itself and the use of the equipment. This mental state is similar to the attitude that many professionals can have due to the accumulation of knowledge or skill with the time. That gives them not the mechanical appearance of a robot but, instead, extreme simplicity while operating equipments. At the same time, they will look as they were forgotten of themselves [4].

\section{Natural and built places as equipment}

By using those concepts it will be reasonable understand that both architectural spaces [5] and urban spaces [6] can be grasped as an identical category of concepts, that means, they are linked equipments which last goal would be to permit to the human to dwell on earth. Natural landscape is, in this way, a background composed by "present-at-hand" entities, over which built spaces are understood as figures. Concerning to architectural and urban studies NorbergSchulz emphasized that the symbolic value of the built space, related to the landscape [7] is a relation similar to the figure and background, concept which he borrowed from Gestalt. It means that the idea that of the totality of the human environment is much more complex than the simple idea that that totality is an addition of those two terms. Norberg-Schulz pointed out that was necessary to understand that the structure of the environment is similar to a universe of linked vertices, which would be the natural and the human built places. The links among both domains represent a continual graduation from the natural to the built environment. Thus, the concept of harmonization would be much more related to a gradual and continual link of values given by human being from natural to human environment structures than a quest for a new kind of aesthetic research. We need now to understand how such universe of links can be integrated by components of IT in order to better strength and improve the continuity from the natural to human domain using Ubicomp.

\section{Ontology of natural and built places}

Maybe the first step to understand how natural and built places could be taken as having the same structure is asking about their similarity in their ontology. When we consider places as equipage to dwell, we should realize about them as equipmental nexus (Fig. 1). 


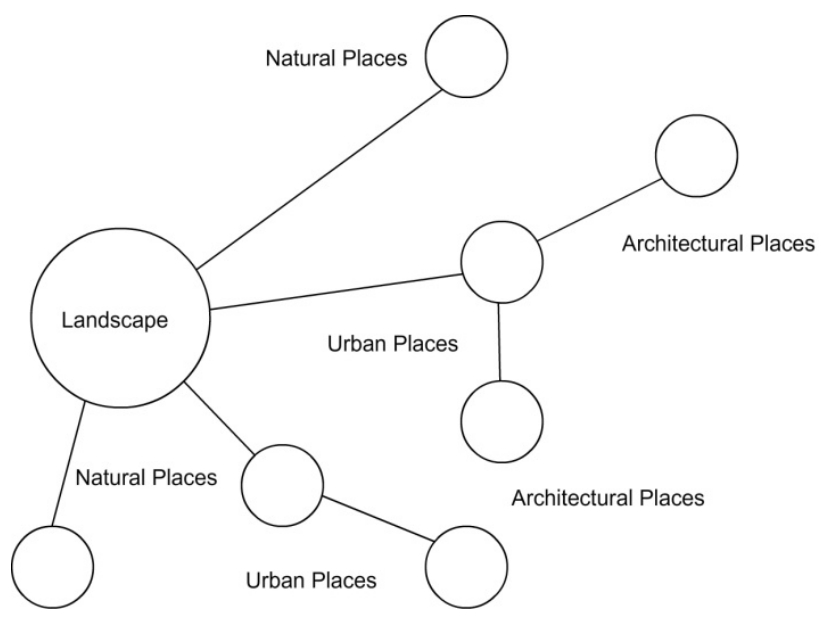

Figure 1: $\quad$ Equipmental nexus of places.

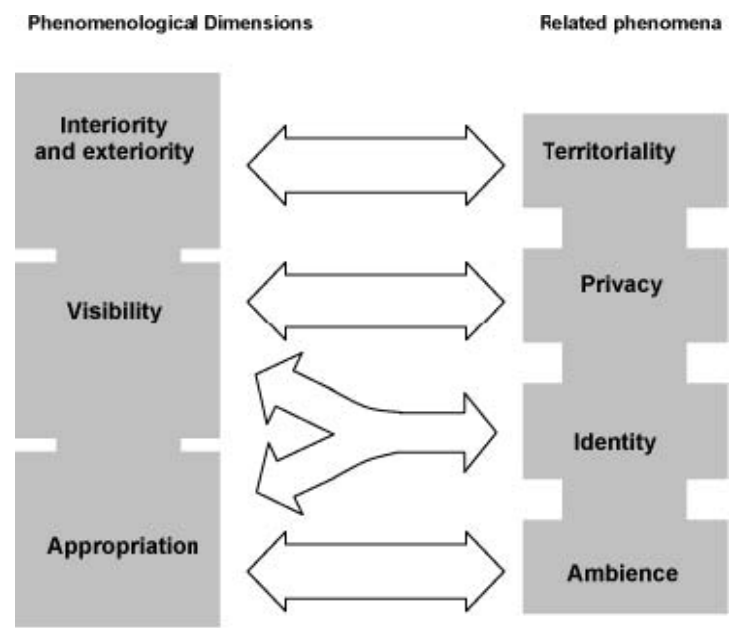

Figure 2: $\quad$ Ontology of places according to Malard [5].

Through the equipmental nexus analysis, natural landscape can be taken as a bigger group that are linked to other more complex structures which, by their turn, are linked to natural and built places (those formers as architectural and urban places). To all those spaces inhabited by human beings, maybe it is possible that the ontological principles pointed out by Malard [5] would be useful to explain how people differentiate spaces into places and attribute them their qualities (Fig. 2) as territoriality, privacy, identity and ambience, which are common to natural and built places. When there is no way to the humans to remain within the natural landscape, being it unfit to live on, we will call them as uninhabitable areas, but we can take them as frames to natural and built places [8]. 
If it is right to assume, as Heidegger did, that when equipments broken down then they start occupying with more visibility our attention, reflecting about places, it would be the absence or dysfunction of the spatial elements of a place what will affect those mentioned qualities [5]. Then, detecting which spatial elements are broken down is a necessary task to improve the qualities of places and detecting them can reveal common categories related to those qualities. We need now to clarify what are the spatial elements of places and how they are related to territoriality, privacy, identity and ambience.

\section{Topology of natural and built places}

The interiority of a place is defined when enclosures (5) delimitates an internal area (2), which has a centrality (1). These elements qualify the place, turning its interior in a territory. Simultaneously, the association of enclosures plus the entrances (6) controls the manner through which the place is connected to the exterior, specifying its privacy and the way it can be visually identified from outside. Human actions inside the delimited internal area in both horizontal and vertical directions would define simultaneously the identity and the appropriation, showing off how people care about that place dedicating it attention and making it with an ambience.

That topology explains how natural and built places can have their elements analyzed through the similar categories in a manner that that analysis puts out how those elements can be correlated to the qualities as territoriality, privacy, identity and ambience.

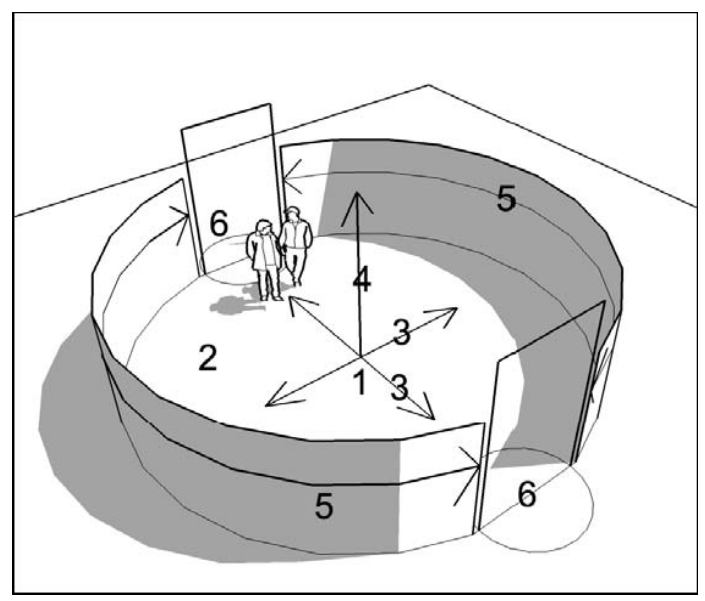

Figure 3: Topological elements of a place studied by Souza [9]: 1) center; 2) internal area; 3) horizontal directions; 4) vertical directions; 5) enclosures, 6) entrances. 


\section{Environmental discontinuity}

It is necessary now to clarify how natural landscape and natural and built places can harmonize through which other. Norberg-Schulz [7] pointed out the need of a conceptual definition similar to what Heidegger called the equipmental nexus, meaning a connection between the internal world of a place and its coherent transition towards the outside natural world. So far we have mentioned that that transition can be grasped as a coherent and continual transition that can be classified according at least three categories: symbolic, functional and technological. Through those categories one can see and analyze the places coherently, graduating from their interior to their exterior but always supporting their main function that is being places to dwell. Thus, we can understand that the harmonization between natural and built places, between landscape and city, would depends upon that graduation, which means it would be the coherency among their symbolic elements, their functional factors and resources, their building resources and technological scene. The whole environment, when we are craving for integrity, would propitiate that the built places, in this way, give us fruition, functionality and would permit being arguable about its build resources while providing a meaningful connection with the natural world. The environmental discontinuity would be the main problem which results in pollution, visual chaos, disorientation and lack of identity in the great urban centers. In the private life nowadays that discontinuity id given by the stylish of the houses of the parvenu, with their interiors looking as museums, detached of the world and isolated, demonstrating the quotation which says "my home is my castle". Those insulars portions of disconnected places, scattered over the world, would obstruct the environmental continuity as nodules of contrast, framed by meaningless spaces as tiresomely long high-ways and uninhabitable areas with landscapes destroyed by human exploitation.

\section{Architects concerned with better places through Ubicomp}

According to John Thackara [10] we live, from some years to nowadays, in a technological dilemma where the most of what is being produced by industries is a response to the fact that the technology allow it to be made, more than a response to real demands of the society. Regarding the truth supporting that point of view, we can say that the focus of the technological development should be the value that the industrial development add to our life more than the innovation it can introduces, showing off itself as a "genial solutions". In other words, our industries are more concerned in how to make things than answering why those things were made, the meaning of those in our daily life.

Reflecting about the use of IT in the last 10 years, some authors considered its influence over the society, some emphasizing internet resources, wondering whether that connectivity would shorten physical distances [11] and create a generalized interactivity based in the pervasiveness of the technology [12]. Using metaphors based in the common sense about space and place, those authors referred to the web connection interfaces as an electronic space or 
cyberspace, that will dissolve the physical place and the city [11]. With the Virtual Reality Technology, those authors imagined that cyberspace would finally offer the subtleness of immersive communication, possible so far in the real world, making unnecessary the real places. Mitchel [13] formulates that there was, in that moment, a crisis in the physical dimension of the place, the region and the city: "Net negates geometry", he said. However, some years later, many of those deterministic predictions did not happen and, instead, at present IT is being studied as part of the material production of spaces, reinforcing the importance of localities and recursively interfering over the design of places. In this sense, reversely the idea of Mitchel, McCullough stated that [14] "contextual computing starts from physical geometry" of the places. Searching for real demands to be responded with the usage of IT applied in the places, architects and environmental designers now are concerned simultaneously about the improvement in the physical conditions and in the communications that support activities in the places. The framework that we are introducing here tries to justify the use of Ubicomp as a search of harmonization between places and landscape. To do so it will need to focus on an ecological view of information.

\section{Conclusion: the framework}

Using the paradigm that the modifications that living systems do in the environment belongs to a linguistic domain [15], we understand that the term "information" should not be used as its mechanical conception in Shannon [16] to whom it was conveyer of meaning. Quite the opposite, spatial organization created by living beings, in the natural environment or built one are tied up with their skill to co-operate among them and adapt themselves. The language, a human privilege, depends upon the concrete environment to create meaning, it means, space is itself information [9]. Humberto Maturana [17] has exemplified the linguistic domains of living systems in the environment as the following picture.

Thus, it is possible to infer that, by an external observer point of view, the physical characteristics of the environment, summed up with the history of its transformations, could be considered as part of a linguistic domain. The skill of a living being to modify its environment to adapt it and survive could be

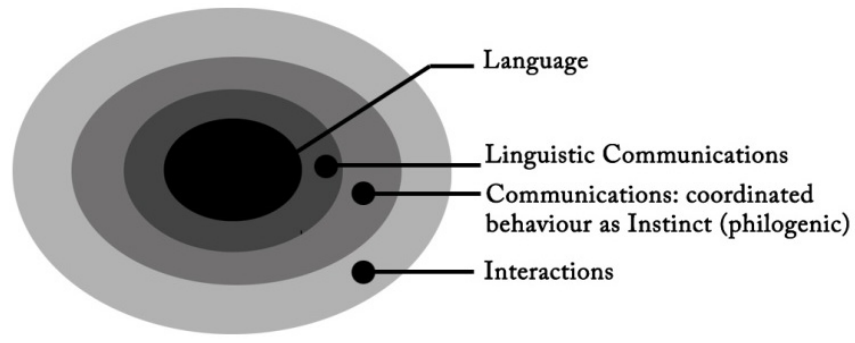

Figure 4: Linguistic domains in the interaction between living systems and their environment [9]. 
understood as a particular kind of communicative behavior, specified through the spatial interactions. Since the environment is modified by the systems that live on it, also could be said that this situation is also communication. But does not mean that the space conveys information: a spatial element is, itself, information. Analysis

Thus, it would be possible to wonder how the spatial elements are correlated to an IT component aiming to reinforce the qualities of places. An analysis [9] has demonstrate that the components of IT, as the sensors, microprocessors, electronic tags, communication links, among others, can be regarded in relation of topological situations which interferes over the qualities of the places. That permitted describing the IT components by means of their positive potential to support local qualities. The following table is part of that analysis [9].

\begin{tabular}{|c|c|c|c|c|c|}
\hline & \multirow{2}{*}{$\begin{array}{l}\text { Territoriality } \\
\text { Interiority and } \\
\text { exteriority }\end{array}$} & \multirow{2}{*}{$\begin{array}{l}\text { Privacy } \\
\text { Visibility }\end{array}$} & \multicolumn{2}{|l|}{ Identity } & \multirow{2}{*}{$\begin{array}{l}\text { Ambience } \\
\text { Appropriation }\end{array}$} \\
\hline & & & Visibility & Appropriation & \\
\hline $\begin{array}{l}\text { Sensors detect } \\
\text { action, measure } \\
\text { physical } \\
\text { quantities such } \\
\text { as temperature, } \\
\text { pressure or } \\
\text { loudness and } \\
\text { convert it into } \\
\text { an electronic } \\
\text { signal of some } \\
\text { kind. }\end{array}$ & $\begin{array}{l}\text { Related to } \\
\text { interiority, for } \\
\text { instance, when they } \\
\text { are able to sense } \\
\text { whether a } \\
\text { moveable element } \\
\text { is inside or outside } \\
\text { a pre-established } \\
\text { territorial } \\
\text { delimitations. }\end{array}$ & $\begin{array}{l}\text { Sensors are related } \\
\text { to privacy by } \\
\text { sensing proximity, } \\
\text { invasion, thus } \\
\text { permitting } \\
\text { surveillance, and } \\
\text { informing when an } \\
\text { action is needed to } \\
\text { react against } \\
\text { invasion. }\end{array}$ & $\begin{array}{l}\text { Sensors could } \\
\text { permit } \\
\text { Identification of } \\
\text { visible users } \\
\text { according their } \\
\text { tag. They could } \\
\text { also Permit users } \\
\text { to identify } \\
\text { specific elements } \\
\text { according to } \\
\text { specific } \\
\text { concerns. }\end{array}$ & $\begin{array}{l}\text { By the use of } \\
\text { 'gesture } \\
\text { sensing' } \\
\text { technology, } \\
\text { they could } \\
\text { Sense } \\
\text { mechanical } \\
\text { movements, } \\
\text { adjustments in } \\
\text { order to tune } \\
\text { the system, } \\
\text { distinguishing } \\
\text { how the user } \\
\text { appropriates } \\
\text { the place. }\end{array}$ & $\begin{array}{l}\text { These could } \\
\text { integrate systems } \\
\text { in order to sense } \\
\text { changes in } \\
\text { temperature, } \\
\text { pressure, light, } \\
\text { when the user tunes } \\
\text { the system, } \\
\text { allowing } \\
\text { information about } \\
\text { how the user } \\
\text { appropriates the } \\
\text { place to be } \\
\text { gathered. These } \\
\text { would permit the } \\
\text { creation of } \\
\text { collections of info } \\
\text { about those } \\
\text { variables in order } \\
\text { to trigger actions. }\end{array}$ \\
\hline
\end{tabular}

Figure 5: Table of correlation between the IT component and the qualities of a place [9].

Using the previous concepts, a framework was created to help the design of the use of IT by architects in the project of urban places. That framework consisted by asking the architects to identify conflicts between spatial elements malfunctioning and the activities they should support. Thus, using the scheme showed in, they explained how the missing or broken down elements were interfering in the four qualities (Fig. 2). Detecting the missing element and interpreting how its interferences were related to spatial attributes, the architects established how a component could be articulated to the space in a system to support the affected activities, using the table above.

By the years of 2005 to 2007, three urban refurbishments were made by architects in UK using the framework described to support the design of the use of IT in the place. It was studied which limits were imposed to qualitative 
solutions when the approach was used partially or in its integrity. A first tem (team A) tried to find pragmatically local problems to given solutions based only in the reflections related to the qualities of place (Fig. 2) without any other theoretical frame. The second team (team B) identified the missing or broken spatial elements in conflict with the activities, given solutions with IT but partially using the framework, which in that time ended with the distinction of elements and services of IT able to be applied in the place (elements to sense the place, to act in the place and to represent the place). The third team (team C) used the whole framework here described, deploying IT components and designing complete systems of Ubicomp. The analyses of the projects before mentioned has demonstrated that team $\mathrm{C}$ used less physical interfering solutions, while team A provided the most intrusive solution, with many physical and expensive recasts.

Those experiments confirmed Mark Weiser's ideas, observing that when an Ubicomp system is designed according to the logic of activities and spatial structure of a place - as the solution of team $\mathrm{C}$ - then physical interferences can be minimized and the technology applied tends to disappear, not being perceived. When otherwise this not happen, as in the solution of team A, the solutions look only as an attempt to exhibit the technological apparatus without a correct concern with local qualities, imprinting a feeling of discontinuation in the environment, making that the function and fruition of the place were stuck in the place.

Reflecting about those experiments, we concluded that when we design creating an environmental continuity with the discrete use of Ubicomp, the harmonization between built elements and the landscape probably is improved by means of the graduation of technological, functional aspects and symbolic value. In this manner, Ubicomp could participate of this process of harmonization between the human and the natural, demanding new research where, instead of posing itself between those former two universes separating them, IT will act as a bridge, and linking the human presence with the world.

\section{Acknowledgement}

We acknowledge the support of FAPEMIG (Foundation to the Support of Research in Minas Gerais) for allowing us to participate in the Eco-Architecture 2010 Conference which allowed us to publish this article.

\section{References}

[1] Weiser, M., The computer for the 21st Century, in ACM SIGMOBILE: Mobile Computing and Communications Review. 1999.

[2] Malpas, J., Heidegger's Topology - Being, Place, World. 2007: MIT press.

[3] Heidegger, M., Being and Time. 1962, London: SCM Press.

[4] Dreyfuss, H.L., Being-in-the-World: A Commentary on Heidegger's Being and Time. 1991, Massachusetts: MIT Press. 
[5] Malard, M.L., Brazilian Low Cost Housing: Interactions and Conflicts between Residents and Dwellings, in Architectural Studies. 1992, University of Sheffield: Sheffield. p. 239.

[6] Souza, R.C., A rua e a sua habitabilidade: Moradores e Espaço Urbano em Situação de Conflito, in Curso de Mestrado em Arquitetura da Escola de Arquitetura da Universidade Federal de Minas Gerais. 1998, Universidade Federal de Minas Gerais Belo Horizonte. p. 172.

[7] Norberg-Schulz, C., Genius loci: towards a phenomenology of architecture 1980, New York: Rizzoli.

[8] Norberg-Schulz, C., Existence, space and architecture 1971, London: Studio Visa.

[9] Souza, R.C., A place-theoretical Framework for the development of IT in urban spaces, in Architecture. 2008, The University of Sheffield: Sheffield. p. 315 .

[10] Thackara, J. The design challenge of pervasive computing. In Computer Human Interaction Forum (CHI 2000). 2000: The Hague.

[11] Virilio, P., The third interval: a critical transition, in Rethinkin Technologies, Andermatt-Conley, Editor. 1993, University of Minnesota: London. p. 3-10.

[12] Stefik, M., Internet dreams: archetypes, myths and metaphors. 1996, Cambridge: MIT press.

[13] Mitchel, W., City of Bits - Space, Place and the Infobahn. 1995, MA: Cambridge: MIT press.

[14] McCullough, M., Digital Ground: architecture, pervasive computing and environmental knowing. 2004: Massachusetts Institute of Technology MIT Press.

[15] Maturana, H., Biology of Language: The Epistemology of Reality, in Psychology and Biology of Language and Thought: Essays in Honor of Eric Lenneberg, G.A. Miller, and Elizabeth Lenneberg, Editor. 1978, Academic Press: New York. p. 27-63.

[16] Shannon, C. and W. Weaver, The Mathematical Theory of Communication. 1949, Urbana: University of Illinois Press.

[17] Maturana, H., Autopoiesis and Cognition: The realization of the Living. 1980, Boston: Reidel Publishing Co. 